\title{
Thermal degradation and flame-retardant properties of epoxy acrylate resins modified with a novel flame retardant containing phosphorous and nitrogen
}

\author{
XIAODONG QIAN ${ }^{a, b}$, QILONG TAI ${ }^{a b}$, LEI SONG ${ }^{a}$, YUAN HU ${ }^{a, b}$, RICHARD K. K. YUEN ${ }^{b, c_{*}}$. \\ a State Key Laboratory of Fire Science, University of Science and Technology of China, 96 \\ Jinzhai Road, Hefei, Anhui 230026, P.R. China. \\ ${ }^{\mathrm{b}}$ USTC-CityU Joint Advanced Research Centre, Suzhou Key Laboratory of Urban Public Safety, \\ Suzhou Institute for Advanced Study, University of Science and Technology of China, 166 Ren'ai \\ Road Suzhou, Jiangsu 215123, P.R. China. \\ ${ }^{\mathrm{c}}$ Department of Building and Construction, City University of Hong Kong, Tat Chee Avenue \\ Kowloon, Hong Kong.
}

\begin{abstract}
A novel monomer containing phosphorus and nitrogen (EBAPP) has been synthesized by allowing phenyl dichlorophosphate to react with ethylenediamine and 2-hydroxyethyl acrylate (HEA). The structure of EBAPP was characterized by FTIR, ${ }^{1} \mathrm{H}$ NMR and ${ }^{31} \mathrm{P}$ NMR. A series of flame-retardant resins was obtained by blending EBAPP with epoxy acrylate (EA) in different ratios and exposing to the UV-light. The flame-retardant properties of the resins were characterized by the limiting oxygen index (LOI) and microscale combustion calorimeter (MCC). The results showed that the incorporation of EBAPP into EA could improve the flame retardancy of EA. The thermal properties of the resins were investigated by thermogravimetric analysis (TGA) in air atmosphere, indicating that EBAPP could improve the char residues at high temperature. Moreover, the thermal degradation of EA/EBAPP resins were investigated by the real-time fourier transform infrared spectra (RTIR) and thermogravimetric analysis/infrared spectrometry (TGA-IR) analysis. The morphologies of the formed chars were observed by scanning electron microscopy (SEM), demonstrating that $20 \mathrm{wt} \%$ of EBAPP in EA exhibited the most effective flame retardancy due to the dense char layers formed during combustion.
\end{abstract}

\section{KEYWORDS: fire chemistry; flame retardants; synthesize.}

\section{INTRODUCTION}

Over the years, light-induced polymerization of multifunctional monomers or oligomers, which transforms rapidly the liquid resins into a solid materials, has found a large variety of applications, in particular to achieve a fast drying of varnishes and printing inks, a quick setting of adhesives and composites materials. ${ }^{[1-4]}$ The commonly used UV curable multifunctional monomers or oligomers include epoxy acrylates, urethane acrylates, unsaturated polyesters and polyester acrylates. Despite having a number of benefits in applications, the resins also have drawbacks, the main of the drawbacks, like other organic polymers, is due to their flammability, which hinders the applications in some areas, especially optical fiber, plastic coatings for electronic accessories and microelectronics. Thus, some research is required to enhance the flame-retardant properties of the resins for their applications in those areas.

Traditionally, there are several approaches which have been used to enhance the flame retardancy of materials. The halogen-containing monomers or oligomers are used to meet the requirement in flameretardant systems, but halogen-type flame retardant polymeric materials give rise to toxic gases and smoke which choke the people and damage the equipments costly. ${ }^{[5,6,7]}$ The layered materials, including layered silicates, manganese oxides, titanates and layered phosphates, have drawn much attention due to their distinct characteristics of superior mechanical, barrier properties, flame retardancy, etc. ${ }^{[8,9,10]}$ But layered materials are not practicable to be incorporated into the UV-curing system, because the addition of layered materials usually causes difficulty in curing during the UV-curing process. Phosphorus containing compounds used in UV-curing have received much attention due to absence of toxic gases and smokes 
during combustion. ${ }^{[11,12,13]}$ It's found that the flame retardants containing both phosphorus and nitrogen elements can make the polymer matrix exhibit higher flame-retardant efficiency in certain materials than those containing phosphorus only due to the synergistic effect between phosphorus and nitrogen. ${ }^{[14,15,16,17]}$ In the previous work, a novel oligomers containing both phosphorus and nitrogen were synthesized, ${ }^{[18]}$ but the high viscosity of the oligomers limits the machining efficiency. Thus, it's necessary to develop a novel reactive monomer containing phosphorus and nitrogen which is beneficial to the UV-curing process.

In this work, a novel monomer (EBAPP) based on phenyl dichlorophosphate, ethylenediamine and 2hydroxylethyl acrylate was designed and synthesized. The thermal and flame-retardant properties of the epoxy acrylates with different EBAPP concentrations were analyzed. The flame retardancy of the cured resins was characterized by the LOI and the thermal behavior of the cured resin was studied by thermogravimetric analysis (TGA). In addition, RTIR and TGA-IR were used to analyze the degradation of EA/EBAPP resins.

\section{EXPERIMENT}

\section{Materials}

Epoxy acrylates, which was supplied by Tianjin Tianjiao Co, is a bisphenol A epoxy acrylate with the unsaturation concentration of $3.73 \mathrm{mmol} / \mathrm{g}$. Phenyl dichlorophosphate was purchased from Deheng Chemical Co. (Shijiazhuang, China), and was freshly distilled before use. Ethylenediamine which was purchased from Shanghai Chemical Reagents Company of China, was distilled before use. 2-hydroxylethyl acrylate (HEA), supplied from Dong-fang Chemical Co, Beijing, China, was distilled at reduce pressure and dried over 4 A molecular sieves before use. Dichloromethane and triethylamine (TEA) were purchased from Shanghai Chemical Reagents Company of China and were also dried over 4 A molecular sieves before use. 2-Hydroxy-2-methyl-1-phenyl-1-propanone (Darocur 1173), kindly supplied by Ciba Specialty Chemicals, was used as a photoinitiator. Other reagents were used as-received without further purification.

\section{Synthesis of EBAPP}

Phenyl dichlorophosphate $(21.1 \mathrm{~g}, 0.1 \mathrm{~mol})$ and dichloromethane $(80 \mathrm{~mL})$ were added into a three-necked flask with an ice-bath equipped with a mechanical stirrer, dropping funnel, flux condenser and nitrogen inlet. After the mixtures were saturated with nitrogen atmosphere, a mixture of HEA (11.6 g, $0.1 \mathrm{~mol})$ and TEA $(21.2 \mathrm{~g}, 0.21 \mathrm{~mol})$ was slowly dropped into the above reaction vessel within 1.5 hours at $0^{\circ} \mathrm{C}$, and then kept at ambient temperature for $2 \mathrm{~h}$. Ethylenediamine $(3 \mathrm{~g}, 0.05 \mathrm{~mol})$, which was predissolved in dichloromethane $(20 \mathrm{ml})$, was then slowly dropped into the above reactant, and kept stirring for another $12 \mathrm{~h}$. Then, the precipitated triethylamine hydrochloride was removed by filtering. The residues were washed with hydrochloric acid, saturated aqueous solutions of sodium bicarbonate and water. After dried over sodium sulphate anhydrous, methylene dichloride was removed by a rotary evaporator, obtaining an orange transparent liquid product named EBAPP (83wt.\%). The schematic process of the reaction is presented in Scheme 1. 


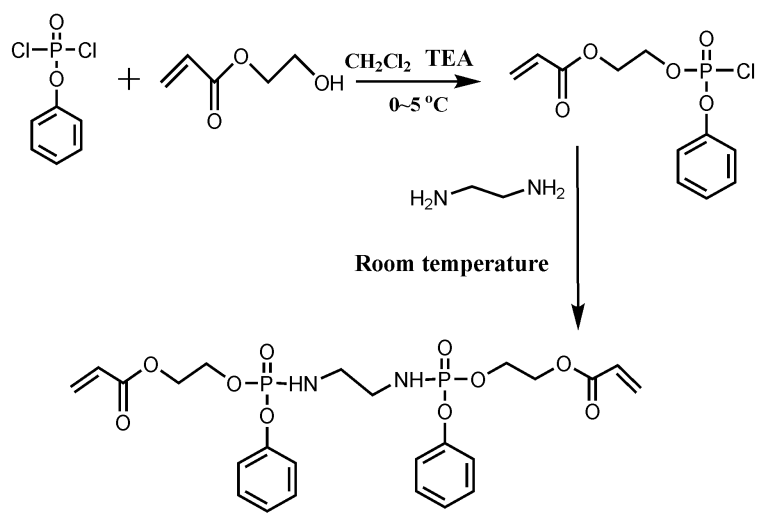

Scheme 1. Synthesis route of EBAPP

${ }^{1} \mathrm{H}$ NMR $\left(\mathrm{CDCl}_{3}\right)$ : 5.84 5.87(CH= $\mathrm{CH}_{2}$, trans $), 6.08 \sim 6.15\left(\mathrm{CH}=\mathrm{CH}_{2}\right.$, cis $), 6.41 \sim 6.46\left(\mathrm{CH}_{2}=\mathrm{CH}_{2}\right), 4.25 \sim 4.39$ $\left(-\mathrm{OCH}_{2} \mathrm{CH}_{2} \mathrm{O}-, \mathrm{N}-\mathrm{H}\right), 3.03 \sim 3.09\left(\mathrm{~N}-\mathrm{CH}_{2}-\right)$.

${ }^{31} \mathrm{P}$ NMR $\left(\mathrm{CDCl}_{3}\right): 4.67$.

FTIR $\left(\mathrm{KBr}, \mathrm{cm}^{-1}\right)$ : 1261(-P=O), 1072, 937(-P-O-C), 1728(-C=O), 1642, 1411, 812(- $\left.\mathrm{CH}_{2}=\mathrm{CH}_{2}-\right), 1597$, 1490(C-H of phenyl), 3235(N-H), 937, 772(-P-N-C).

Table 1 The composition and LOI values of EA/EBAPP resin with different EBAPP contents.

\begin{tabular}{ccccccr}
\hline Sample & $\begin{array}{c}\text { Epoxy } \\
\text { acrylate } \\
(\mathbf{g})\end{array}$ & $\begin{array}{c}\text { EBAPP } \\
(\mathbf{g})\end{array}$ & $\begin{array}{c}\text { EBAPP } \\
\text { content } \\
\mathbf{( w t \% )}\end{array}$ & $\begin{array}{c}\text { Phosphorus } \\
\text { content } \\
\mathbf{( w t \% )}\end{array}$ & $\begin{array}{c}\text { Nitrogen } \\
\text { content } \\
(\mathbf{w t} \%)\end{array}$ & LOI \\
\hline EA0 & 15.0 & 0 & 0 & 0 & 0 & $21.0 \pm 0.5$ \\
EA10 & 13.5 & 1.5 & 10 & 1.05 & 0.4 & $28.0 \pm 0.5$ \\
EA20 & 12.0 & 3.0 & 20 & 2.10 & 0.8 & $29.0 \pm 0.5$ \\
EA30 & 10.5 & 4.5 & 30 & 3.15 & 1.2 & $28.5 \pm 0.5$ \\
\hline
\end{tabular}

\section{Sample preparation}

The mixtures of EA with EBAPP in different ratios were stirred fully to get various homogenous blends according to Table 1. The samples were put in the UV irradiation apparatus in the presence of $3 \mathrm{wt} \%$ Darocur 1173 and were irradiated for 20 second. The ultraviolet light source used for irradiation is a lamp ( $80 \mathrm{~W} / \mathrm{cm}$; Lantian Co., Beijing, China) that emits light in the near UV (characterized wavelength, 340 360 $\mathrm{nm}$ ). As a result, the flame retardant resins were obtained in the ratios of $10 \mathrm{wt} \%$ (EA10), 20wt\% (EA20), $30 \mathrm{wt} \%(\mathrm{EA} 30)$.

\section{Measurement}

FTIR spectroscopy (Nicolet 6700 FT-IR spectrophotometer) was employed to characterize EBAPP using thin $\mathrm{KBr}$ disc. The transition mode of the FTIR was used and the wavelength range was set from 4000 to $500 \mathrm{~cm}^{-1}$. ${ }^{1} \mathrm{H}$ NMR and ${ }^{31} \mathrm{P}$ NMR measurements were conducted on AVANCE 400 Bruker spectrometer at room temperature using $\mathrm{CDCl}_{3}$ as solvent. According to ASTM D2863, the specimens used for the test were of dimensions $100 \times 6.5 \times 3 \mathrm{~mm}^{3}$. The limiting oxygen index (LOI) values were measured on an HC-2 oxygen index meter (Jiangning Analysis Instrument Company, China). The thermogravimetric analysis (TGA) was carried out on TGA Q5000 IR thermogravimetric analyzer (TA instruments). About 4$10 \mathrm{mg}$ of UV-cured resins heated from room temperature to $800{ }^{\circ} \mathrm{C}$ at the heating rate of $20^{\circ} \mathrm{C} / \mathrm{min}$ under air purge. A GOVMARK MCC-2 microscale combustion calorimeter (MCC) was used to investigate the 
combustion of the UV-cured resins. According to the standard of ASTM D7309-07, about 5 mg samples of UV-cured resins were heated to $800{ }^{\circ} \mathrm{C}$ at heating rate of $1{ }^{\circ} \mathrm{C} / \mathrm{s}$ and in a stream of nitrogen flowing at $80 \mathrm{~cm}^{3} / \mathrm{min}$. Real-time fourier transform infrared spectra (RTIR) were recorded using the Nicolet $6700 \mathrm{FT}$ IR spectrophotometer equipped which has a heating device. The cured samples were grinded with $\mathrm{KBr}$ powder and the mixtures were pressed into a tablet. The table was placed in the oven and heated at raising temperature at the heating rate of $10^{\circ} \mathrm{C} / \mathrm{min}$. The RTIR spectras were obtained in situ during the thermooxidative degradation of the samples. Thermogravimetric Analysis/Infrared spectrometry (TG-IR) of the cured sample was carried out by using the TGA Q5000 IR thermogravimetric analyzer which was interfaced to the Nicolet 6700 FTIR spectrophotometer. About $4.0 \sim 10.0 \mathrm{mg}$ of the UV cured sample was heated from room temperature to $800^{\circ} \mathrm{C}$ at the heating rate of $20^{\circ} \mathrm{C} / \mathrm{min}$. The scanning electron microscope (SEM) of the char residues were performed with a scanning electron microscope AMRAY1000B. The samples were sputter-coated with a gold conductive layer.

\section{RESULT AND DISCUSSION}

\section{Characterization of EBAPP}

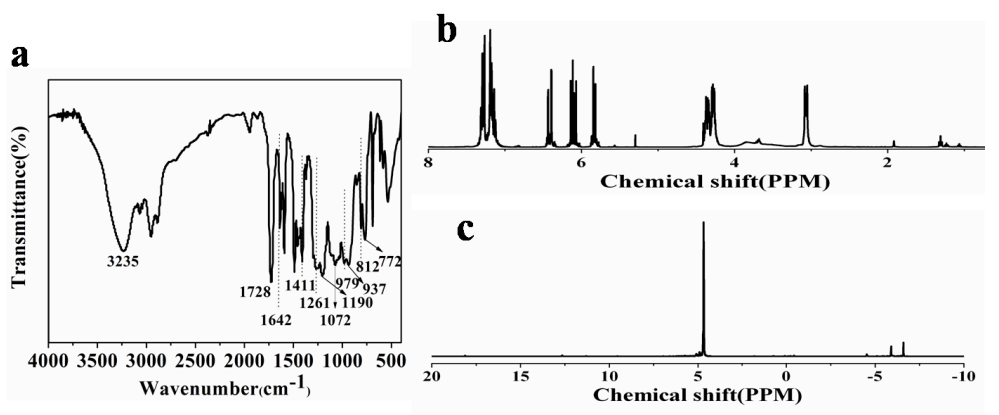

Figure 1. The FTIR spectra of $\operatorname{EBAPP}(a),{ }^{1} \mathrm{H}$ NMR(b) and ${ }^{31} \mathrm{P}$ NMR(c) spectra of EBAPP.

The chemical structures of EBAPP were characterized by FTIR, ${ }^{1} \mathrm{H}$ NMR and ${ }^{31} \mathrm{P}$ NMR. The FTIR spectrum of EBAPP is shown in Figure 1-a. The peak at $1261 \mathrm{~cm}^{-1}$ belongs to the stretching vibrations of $\mathrm{P}=\mathrm{O}$. The peaks at both $1072 \mathrm{~cm}^{-1}$ and $937 \mathrm{~cm}^{-1}$ correspond to the stretching vibrations of $\mathrm{P}-\mathrm{O}-\mathrm{C}$ and the peaks at both $937 \mathrm{~cm}^{-1}$ and $772 \mathrm{~cm}^{-1}$ are due to the bond of P-N-C. Moreover, the strong absorption bands at $1728,1642,1411$ and $812 \mathrm{~cm}^{-1}$ indicate the existence of acrylate groups. ${ }^{[18]}$ The ${ }^{1} \mathrm{H}$ NMR and ${ }^{31} \mathrm{P}$ NMR spectra of EBAPP are shown in Figure 1-b and Figure 1-c, respectively. It shows three groups of characteristic peaks at 5.84 6.46ppm, which proves the existence of $-\mathrm{CH}=\mathrm{CH}_{2}$ in EBAPP. The peaks observed at 3.03 3.09ppm are assigned to the $\mathrm{H}$ atoms of $\mathrm{N}_{-} \mathrm{CH}_{2}$. And the peaks at $4.25 \sim 4.39 \mathrm{ppm}$ belong to $-\mathrm{O}-\mathrm{CH}_{2}-\mathrm{CH}_{2}-\mathrm{O}$ - and $\mathrm{N}-\mathrm{H}$. Moreover, the peaks observed at 7.12 7.33ppm are obviously signs of $\mathrm{H}$ atoms attached with phenyl group. The ${ }^{31} \mathrm{P}$ NMR of EBAPP shows the signal that there is one main peak. The ${ }^{31} \mathrm{P}$ NMR indicates that there are around $10 \%$ impurities in the EBAPP, the impurities are due to the unreacted or the half-reacted phosphorus. Those indicate that the EBAPP has been successfully synthesized.

\section{Flame-retardant properties and thermal stability of the resins}

According to ASTM D2863, LOI which is used to test the flammability of materials is a quantitative method. The LOI values of the resins are shown in Table 1. The LOI increases from 21 to 29 when EBAPP increases from 0 to $20 \mathrm{wt} \%$. The results indicate that EBAPP exhibits good flame-retardant effect to epoxy acrylates. However, when the EBAPP content reached $30 \mathrm{wt} \%$, the LOI values decreased slightly. Those 
results indicate that the loading of $20 \mathrm{wt} \%$ EBAPP exhibits excellent flame-retardant properties compared with the loading of $30 \mathrm{wt} . \%$, which are due to the properties loadings of nitrogen elements.

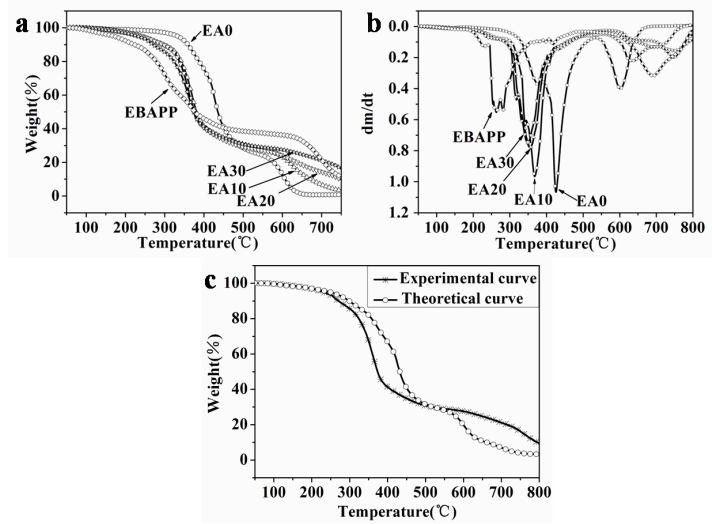

Figure 2. TGA(a) and DTG(b) curves of the EA and EA/ EBAPP blends in air atmosphere, the calculation of the weight loss curve of EA30 and experimental curve of EA30 (c).

Table 2 The thermogravimetric data of the polymers in air

\begin{tabular}{ccccc}
\hline Samples & $\mathbf{T}_{\mathbf{0 . 1}}\left({ }^{\mathbf{0}} \mathbf{C}\right)$ & $\mathbf{T}_{\mathbf{0 . 5}}\left({ }^{\mathbf{0}} \mathbf{C}\right)$ & $\mathbf{T}_{\mathbf{m a x}}\left({ }^{\mathbf{0}} \mathbf{C}\right)$ & $\mathbf{C h a r}\left(\mathbf{7 0 0}{ }^{\mathbf{0}} \mathbf{C}\right)$ \\
\hline EA0 & 357 & 435 & 425 & 0.91 \\
EA10 & 303 & 382 & 367 & 6.85 \\
EA20 & 302 & 376 & 353 & 13.69 \\
EA30 & 260 & 374 & 344 & 20.89 \\
\hline
\end{tabular}

$\mathrm{T}_{0.1}\left({ }^{\circ} \mathrm{C}\right)$ and $\mathrm{T}_{0.5}\left({ }^{\circ} \mathrm{C}\right)$ are the $10 \mathrm{wt} \%$ and $50 \mathrm{wt} \%$ weight loss temperature;

$\mathrm{T}_{\max }$ is the temperature that the degradation rate reached a maximum;

Char $\left(700^{\circ} \mathrm{C} \mathrm{wt} \%\right)$ is the char residue by weight at $700{ }^{\circ} \mathrm{C}$.

The thermal stabilities and thermal degradation process of resins were investigated by TGA under air atmosphere. The TGA and derivative thermogravimetric (DTG) curves mainly involve the stages of the release of decomposition products and the formation of chars (Figure 2). Different data from the TGA of the resins are collected in Table 2 . As for the oxidative degradation of neat EA, the UV-cured resins begin to lose its weight at about $320^{\circ} \mathrm{C}$ and degrades almost completely before $650^{\circ} \mathrm{C}$. Two differential thermogravimetry (DTG) peaks at $420^{\circ} \mathrm{C}$ and $610^{\circ} \mathrm{C}$ are observed, corresponding to two decomposition stages respectively. During the first degradation stage $\left(220-510^{\circ} \mathrm{C}\right)$, some complex chemical reactions take place which include the free radical chain scission of the methylene linkage and crosslinking reactions of molecular chains induced by oxygen. ${ }^{[17]}$ In the second stage, the macromolecular chains of EA and the previous formed char are further oxidized and more small molecular degradation products are released.

Figure 2-a shows the TGA curve of EBAPP under air atmosphere. The cured EBAPP exhibited a 5\% weight loss at $200^{\circ} \mathrm{C}$ and a $10 \%$ weight loss at $240^{\circ} \mathrm{C}$. The degradation process of EBAPP can be divided into two steps: the first region is due to the decomposition of $\mathrm{P}-\mathrm{O}-\mathrm{C}$ bonds and the formation of char, which can be confirmed by the RTIR analysis. The second region is attributed to the decomposition of unstable char. ${ }^{[18]}$ The $T_{d}$ (the temperature at which the weight loss is 5\%) of EBAPP is lower than that of pure epoxy acrylates. The TGA and DTG curves of EA10, EA20 and EA30 in air are shown in Figure 2-b. It is noted that the onset of the thermal degradation of the flame retardant resins shifts significantly towards the lower temperature range compared with pure EA. Generally, the reduction of the initial degradation temperature may be attributed to the lower stability of the flame retardants. But when the temperature is higher than 470 ${ }^{\circ} \mathrm{C}$, the flame-retardant resins exhibits more thermally stable than that of pure EA. That's because when heated at $250-300^{\circ} \mathrm{C}$, the phosphonates degrades first and formed phosphoric acid and the obtained phosphoric acid could act as an acid catalyst, accelerating the degradation of EA. ${ }^{[18]}$ The obtained 
phosphoric acid can react with the decomposition products of EA, resulting in the formation of condensed char layers, which can be confirm by the RTIR and TEM results.

In order to further determine whether EBAPP affects the char forming or not, the weight difference curves between experimental and calculated TGA curves were computed ${ }^{[19]}$, as shown in Figure 2-c. It is distinct that the initial degradation temperature of EA30 is lower at the temperature ranging from $290^{\circ} \mathrm{C}$ to $500^{\circ} \mathrm{C}$ compared with the theoretical curve. But when the temperature is higher than $500{ }^{\circ} \mathrm{C}$, the char residue of EA30 is higher than the theoretical char residues. Thus, there are synergistic effect between EA and EBAPP and some reactions taking place between them. In other words, EBAPP could promote the char formation which could effectively protect the underlying materials from further degradation.

\section{Combustion properties of EA/EBAPP resins}

Table 3 The MCC data of EA and EA/EBAPP resins

\begin{tabular}{cccc}
\hline Sample & $\begin{array}{c}\text { THR } \\
(\mathbf{k J} / \mathbf{g})\end{array}$ & $\begin{array}{c}\text { Peak HRR } \\
(\mathbf{W} / \mathbf{g})\end{array}$ & $\begin{array}{c}\mathbf{T}_{\max } \\
\left({ }^{\mathbf{0}} \mathbf{C}\right)\end{array}$ \\
\hline EA0 & 21.2 & 332.0 & 440.9 \\
EA10 & 13.3 & 204.4 & 380.9 \\
EA20 & 13.6 & 155.2 & 363.7 \\
EA30 & 12.8 & 140.8 & 359.1 \\
\hline $\mathrm{T}_{\max }$ is the temperature corresponding to the Peak HRR.
\end{tabular}

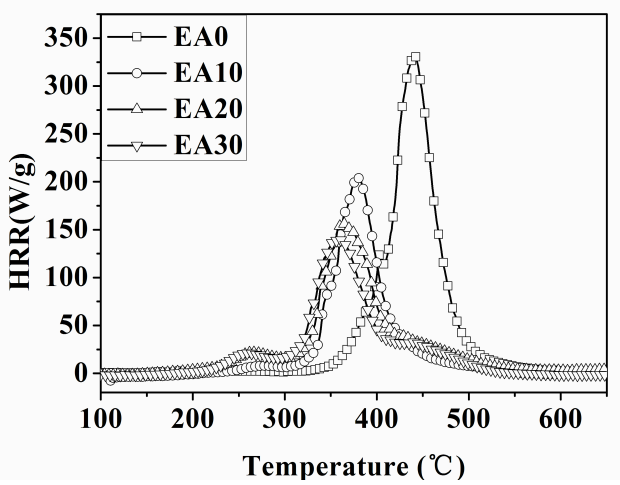

Figure 3. The HRR curves of the EA0 and EA/EBAPP resins at $1 \mathrm{~K} / \mathrm{s}$ heating rate

Microscale combustion calorimeter (MCC) is a quantitative analytical laboratory test and it provides a wealth of information on the combustion behaviour of polymer, so it was one of the most effective small scale methods to invest the combustion properties of materials. ${ }^{[20]}$

Figure 3 shows the heat release rate (HRR) curves of EA, EBAPP and their blends in different ratios and the corresponding combustion data are presented in Table 3. It is found that the THR and pHRR of EA are as high as $21.2 \mathrm{~kJ} / \mathrm{g}$ and $332.0 \mathrm{~W} / \mathrm{g}$ respectively. Compared with pure EA, the pHRR of the samples containing $30 \mathrm{wt} \%$ of EBAPP decreases from $332 \mathrm{~W} / \mathrm{g}$ to $140.8 \mathrm{~W} / \mathrm{g}$. Moreover, the THR of $30 \mathrm{wt} \%$ EBAPP decreases from $21.2 \mathrm{~kJ} / \mathrm{g}$ to $12.8 \mathrm{~kJ} / \mathrm{g}$. From above data, it can be concluded that the presence of phosphorus and nitrogen are responsible for the reduced PHRR and THR. It's known that the decomposition products of EA are mainly bisphenol A monomer, the derivatives of bisphenol A and some alkanes, which are highly flammable. It is not surprising that the EA has a high value of pHRR and THR. The introduction of EBAPP into EA can reduce the amounts of combustible compounds. That's because most phosphorousnitrogen containing compounds release non-flammable products such as $\mathrm{CO}_{2}, \mathrm{NH}_{3}$, phosphorous compounds, $\mathrm{N}_{2}$, etc. during decomposition and those products can dilute the hot atmosphere and cool pyrolysis zone. ${ }^{[21]}$ The temperature at maximum pyrolysis rate $\left(\mathrm{T}_{\max }\right)$ decreases with the increasing of EBAPP content. That's because when heated at low temperature, phosphorus degrades first and formed phosphoric acid. The obtained phosphoric acid acts as an acid catalyst, which accelerates the chain scission 
of methylene linkages and the breaking of ester groups in EA at $300 \sim 450^{\circ} \mathrm{C}$. This result is in accordance with the TGA results.

\section{Structural characterization of volatilized products}

$\mathbf{a}$

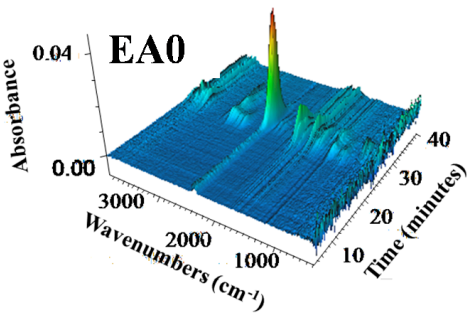

b

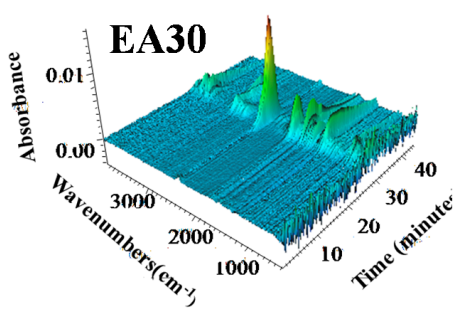

c

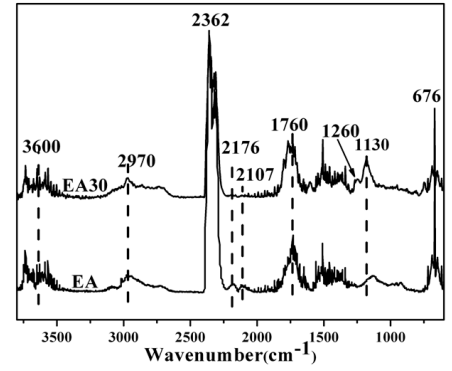

Figure 4. The 3D TGA-FTIR spectra of EA0(a) and EA30(b); (c): the FTIR spectrum of pyrolysis products for EA and EA30 at the maximum decomposition rate.
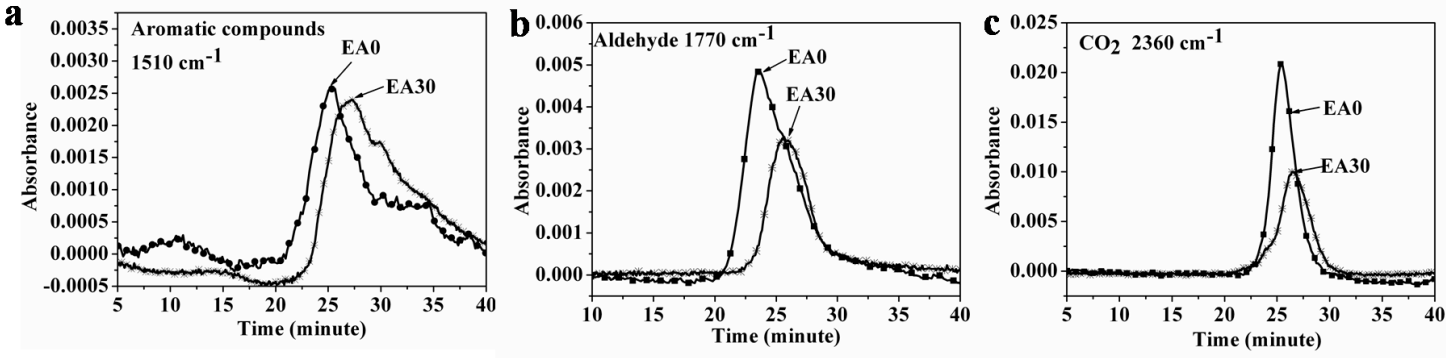

Figure 5. Absorbance of pyrolysis products for EA and EA30 vs time: $\mathrm{CO}_{2}$; aldehyde and aromatic compounds

The TGA-FTIR technique can gives the direct information of the volatilized products which can significantly contribute to an understanding of thermal degradation mechanisms of EA/EBAPP resins. The 3D TGA-FTIR spectra of gas phase in the thermal degradation of EA and EA30 at maximum decomposition rates are shown in Figure 4. The main share bonds of the decomposition products is attributed to the functional groups with characteristic, unambiguous bond positions, such as water (around $3500 \sim 3800 \mathrm{~cm}^{-1}$ ), compounds containing alkane (around 2900 3000 $\mathrm{cm}^{-1}$ ) and compounds containing aromatic ring (around 1400 1600 $\mathrm{cm}^{-1}$ ). Some small molecular gaseous species, $\mathrm{CO}_{2}, \mathrm{CO}$, methane, aromatic are easily identified by their characteristic absorbance: $\mathrm{CO}_{2}\left(2360 \mathrm{~cm}^{-1}\right), \mathrm{CO}\left(2176,2107 \mathrm{~cm}^{-1}\right)$, $\mathrm{CH}_{4}\left(3015 \mathrm{~cm}^{-1}\right)$, aromatic $\left(676 \mathrm{~cm}^{-1}\right) \cdot{ }^{[22]}$ The peak around $1760 \mathrm{~cm}^{-1}$ indicates the volatilized products containing carbonyl are released. Moreover, the disappearance of the characteristic peaks at 2176 and 2107 $\mathrm{cm}^{-1}(\mathrm{CO})$ indicates that EBAPP can probably suppress the production of $\mathrm{CO}$ during combustion. The new peak appeared at around $1260 \mathrm{~cm}^{-1}$ is stretching vibration of $\mathrm{P}=\mathrm{O}$, which indicates that there exists phosphorus and its derivants in the gaseous phase. Moreover, the characteristic absorptions at both 1118 $\mathrm{cm}^{-1}$ (-P-O-P-O) and $924 \mathrm{~cm}^{-1}(-\mathrm{P}-\mathrm{O}-\mathrm{Ph})$ are not distinct which were overlapped by that of the EA matrix. Due to radical trapping of phosphorus in both gas phase and solid phase as well as the dilution effect of nitrogen ${ }^{[22-25]}$, both phosphorus and nitrogen play an important role in the flame retardancy of EA. The emissions of volatilized products during the thermal degradation of EA/EBAPP resins are shown in Figure 5. It's obvious that the gas release time of EA30 is later than pure EA. The absorbance intensity of 
pyrolysis products for EA30 is lower than that of EA. Consequently, the addition of EBAPP can reduce the release of combustible gas.

\section{Structural characterization of condensed phase}
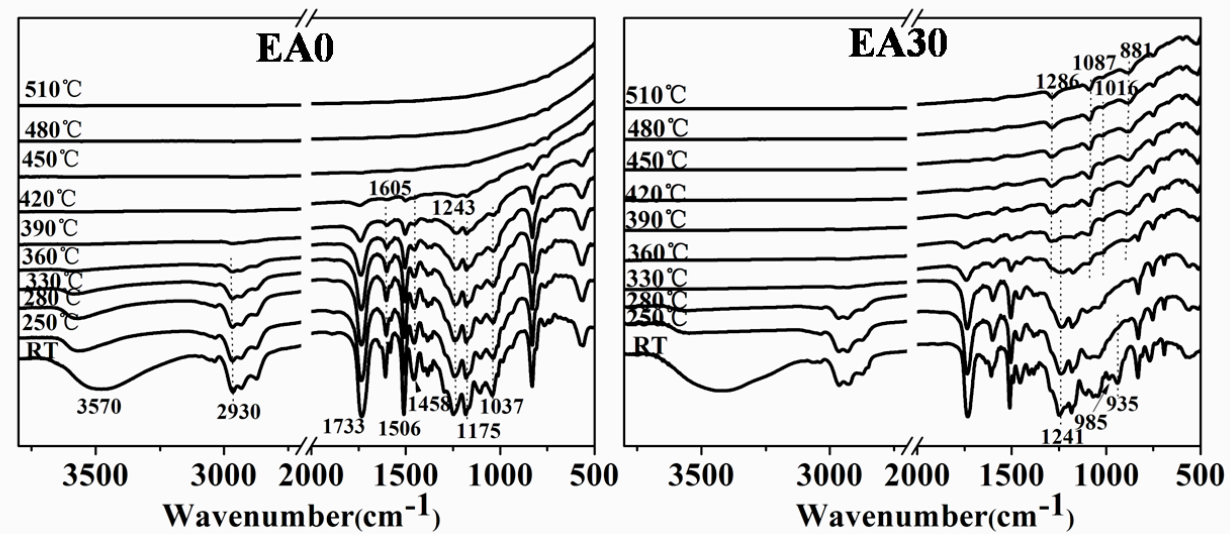

Figure 6. The dynamic FTIR spectra of EA0 and EA30 at different pyrolysis temperatures.

In order to investigate the changes of the chemical structure in the condensed phase, EA0 and EA30 were chosen to measure the changes in spectra of FTIR, as shown in Figure 6. As for pure EA, it is noted that peaks at $3570,2930,1733,1605,1506,1458,1243$, and $1037 \mathrm{~cm}^{-1}$ are the characteristic absorptions of EA. The bond at $3570 \mathrm{~cm}^{-1}$ nearly disappears at the temperature of $360^{\circ} \mathrm{C}$, which can be explained by the releasing of water and the early decomposing of $-\mathrm{OH}$ bound. As the temperature elevates, the relative intensities of other characteristic peaks do not change below $330{ }^{\circ} \mathrm{C}$. However, when the temperature reaches $420^{\circ} \mathrm{C}$, it's found that the absorption peaks at 2930, 1733, 1605, 1506, 1458, 1243, 1175 and 1037 $\mathrm{cm}^{-1}$ disappear completely, indicating that the main decomposition happens around the temperature of 400 ${ }^{\circ} \mathrm{C} .{ }^{[26,27]}$ This result is in accordance with the TGA results $\left(\mathrm{T}_{\max }\right.$ is $\left.425^{\circ} \mathrm{C}\right)$. As for EA30, the characteristic peaks of EBAPP are not obvious because its characteristic band probably coincide with those of the EA matrix. Moreover, the quick decrease in relative intensities at $935 \mathrm{~cm}^{-1}$ (from $25{ }^{\circ} \mathrm{C}$ to $250{ }^{\circ} \mathrm{C}$ ) clearly indicates the complete degradation of P-O-C aliphatic structure. ${ }^{[15]}$ The peak at $1241 \mathrm{~cm}^{-1}$ (the stretching vibration of $\mathrm{P}=\mathrm{O}$ bond) shifts to $1295 \mathrm{~cm}^{-1}$. The peaks at $1295 \mathrm{~cm}^{-1}$ can be assigned to stretching vibration for $\mathrm{P}-\mathrm{O}-\Phi$ structure, where $\Phi$ represents the graphite-like polynuclear aromatic structure. ${ }^{[28,29]}$ Those indicate that the phosphorus group deviates from the aliphatic structure and forms the P-O- $\Phi$ structure at the temperature around $360^{\circ} \mathrm{C}$. Moreover, three new peaks appear at 881,1016 and $1087 \mathrm{~cm}^{-1}$ above 330 ${ }^{\circ} \mathrm{C}$. The peaks at $1016 \mathrm{~m}^{-1}$ can be assigned to the bonds of P-O-Ph, and the peaks at $1087 \mathrm{~cm}^{-1}$ and $881 \mathrm{~cm}^{-1}$ are attributed the P-O-P bond in the polyphosphoric acid structures. ${ }^{[29]}$ The three peaks $(1286,1087$, and $\left.881 \mathrm{~cm}^{-1}\right)$ are attributed to phosphoric andride $\left.(\mathrm{P}=\mathrm{O})-\mathrm{O}-\mathrm{P}\right)$ species. As a result, it can be concluded that some phosphorus groups linked each other by sharing one oxygen atom. The $\mathrm{P}-\mathrm{O}-\mathrm{P}$ and $(\mathrm{P}=\mathrm{O})-\mathrm{O}-\mathrm{P}$ groups can be regarded as crosslinkers which link to different aromatic species. The summary of RTIR results specifies that the thermal degradation of EA/EBAPP resins can be approximately separated into three portions: the scissions of the least stable P-O-C aliphatic structures, the decompositions of aliphatic groups, and the formations of $\mathrm{P}-\mathrm{O}-\mathrm{P},(\mathrm{P}=\mathrm{O})-\mathrm{O}-\mathrm{P})$ and $\mathrm{P}-\mathrm{O}-\Phi$ complex structures. 


\section{Morphologic structures of the charred crusts}

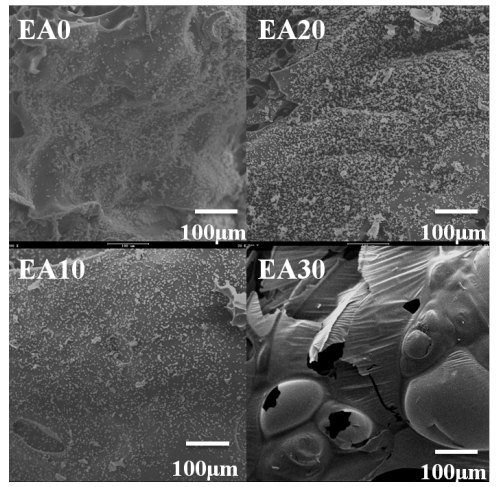

Figure 7 . The SEM of char residues $(\times 200)$ : EA0; EA10; EA20; EA30.

Figure 7 shows the SEM micrograph of the char from combustion of EA/EBAPP resins (EA0, EA10, EA20 and EA30) at $600{ }^{\circ} \mathrm{C}$ in muffle for $10 \mathrm{~min}$. Compared with pure EA, the chars of EA10 and EA20 had a continuous and compact framework which could resist both mass and heat transfer. When the EBAPP content reached $30 \mathrm{wt} \%$, the char of EA30 has large numbers of holes distributed over the surface of chars and the diameters of the holes were all large, ranging from $100 \mu \mathrm{m}$ to $200 \mu \mathrm{m}$. Moreover, some holes penetrating deeply into underlying material of the surface were observed, indicating that the decomposition of EA30 released a lot of gaseous products which might penetrate through the char. Compared with EA10 and EA20, the condense chars were formed in the initial stage due to the high loading of both phosphorus and nitrogen and the catalysis of phosphoric acid in EA30. As a result, the generated gases stayed locked in the thermal decomposition zone. However, when the proper temperature is reached, the generated gas may break through the char, resulting in the loosen holes and the bubbles. Thus, the better flame retardant efficiency of EBAPP is based on the balance of the effects in the condensed phase and gaseous phase which was further proved by the SEM result. Thus, this result is consistent with the LOI result that EA20 had the highest LOI value due to the better balance of the effects in condensed phase and gaseous phase.

\section{CONCLUSION}

In this work a series of epoxy acrylates/EBAPP resins containing different ratios of EBAPP were prepared. The TGA and DTG analysis reveal that the high loadings of phosphorus and nitrogen contribute great to the high char residues and notably enhance the thermal stability at high temperature. The MCC results reveal that the incorporation of EBAPP into EA could lower pHRR and THR of EA compared with those of the pure EA, indicating an improvement on the flame retardancy of EA. The thermal degradation of EA/EBAPP resins is further discussed by the RTIR and TGA-IR results. The thermal degradation of EA/EBAPP resins can be approximately separated into three portions: the scissions of the least stable P-O$\mathrm{C}$ aliphatic structures, the decompositions of aliphatic groups, and the formations of $\mathrm{P}-\mathrm{O}-\mathrm{P}$, and $(\mathrm{P}=\mathrm{O})-\mathrm{O}-$ P) complex structures. The better flame retardant efficiency of EBAPP is based on the balance of the effects in the condensed and gaseous phases which are further proved by the SEM result, indicating that EA20 has better balance.

\section{ACKNOWLEDGEMENTS}

The work was financially supported the joint fund of NSFC and Guangdong Province (No. U1074001), National Natural Science Foundation of China (No. 51303167) 


\section{REFERENCES}

[1] Decker, C., (2002) Kinetic study and new applications of UV radiation curing, Macromolecular Rapid Communications, 23:1067-1093, http://onlinelibrary.wiley.com/doi/10.1002/marc.200290014/full.

[2] Decker, C., et al., (2002) Ultrafast synthesis of bentonite-acrylate nanocomposite materials by UVradiation curing. Journal of Materials Science,. 37:4831-4838,

http://link.springer.com/article/10.1023/A\%3A1020818414927\#.

[3] Keller, L., et al.,(2004) Synthesis of polymer nanocomposites by UV-curing of organoclay-acrylic resins, Polymer,45:7437-7447, http:/www.sciencedirect.com/science/article/pii/S0032386104008158.

[4] Decker, C., (1998) The use of UV irradiation in polymerization, Polymer International, 45:133-141, http://onlinelibrary.wiley.com/doi/10.1002/(SICI)1097-0126(199802)45:2\%3C133::AID-

PI969\%3E3.0.CO;2-F/abstract.

[5] Dvir, H. and Gottlieb M., (2006) A reactive flame retardant as a poly(propylene)-sized glass adhesion promoter, Macromolecular Materials and Engineering, 291:913-916,

http://onlinelibrary.wiley.com/doi/10.1002/mame.200600010/full.

[6] Janak, K., et al, (2008) Enantiomer-specific accumulation of hexabromocyclododecanes in eggs of predatory birds, Chemosphere,73:193-200,

http://www.sciencedirect.com/science/article/pii/S004565350800307X.

[7] Alaee, M., et al., (2003) An overview of commercially used brominated flame retardants, their applications, their use patterns in different countries/regions and possible modes of release, Environment International, 29: 683-689, http://www.ncbi.nlm.nih.gov/pubmed/12850087.

[8] Hussain, M., et al.,(2006) Effect of organo-phosphorus and nano-clay materials on the thermal and fire performance of epoxy resins. Journal of Applied Polymer Science, 2004. 91:1233-1253, http://onlinelibrary.wiley.com/doi/10.1002/app.13267/full.

[9] Hao, X.Y., et al., Flame retardancy and antidripping effect of OMT/PA nanocomposites, Materials Chemistry and Physics, 96:34-41, http://www.sciencedirect.com/science/article/pii/S0254058405004153.

[10] Seo, W.J., et al., (2006) Effects of ultrasound on the synthesis and properties of polyurethane foam/clay nanocomposites, Journal of Applied Polymer Science, 102:3764-3773, http://onlinelibrary.wiley.com/doi/10.1002/app.24735/full.

[11] Perez, R.M., et al., (2006) Effective halogen-free flame retardants for carbon fibre-reinforced epoxy composites, Journal of Materials Science, 41:4981-4984, http://link.springer.com/article/10.1007\%2Fs10853-006-0134-4?LI=true\#.

[12] He, Q.L., et al., (2009) Synergistic effects of polyhedral oligomeric silsesquioxane (POSS) and oligomeric bisphenyl A bis(diphenyl phosphate) (BDP) on thermal and flame retardant properties of polycarbonate, Journal of Materials Science, 44:1308-1316, http://link.springer.com/article/10.1007/s10853-009-3266-5\#.

[13] Zhong, H.F., et al., (2007) Synthesis, characteristic of a novel additive-type flame retardant containing silicon and its application in PC/ABS alloy, Journal of Materials Science, 42:10106-10112, http://link.springer.com/article/10.1007/s10853-007-2062-3\#.

[14] Chen, X.L., et al., (2008) Preparation and thermal properties of a novel UV-cured star polyurethane 
acrylate coating, Polymers for Advanced Technologies, 19:322-327,

http://onlinelibrary.wiley.com/doi/10.1002/pat.995/abstract.

[15] Shieh, J.Y. and Wang C.S., (2001) Synthesis of novel flame retardant epoxy hardeners and properties of cured products, Polymer, 42(18): 7617-7625,

http://www.sciencedirect.com/science/article/pii/S0032386101002579.

[16] Jiao, C.M. and Chen X.L.,(2010) Flammability and Thermal Degradation of Intumescent FlameRetardant Polypropylene Composites, Polymer Engineering and Science, 50: 767-772,

http://onlinelibrary.wiley.com/doi/10.1002/pen.21583/abstract.

[17] Leu, T.S. and Wang C.S., (2004) Synergistic effect of a phosphorus-nitrogen flame retardant on engineering plastics, Journal of Applied Polymer Science, 92:410-417, http://onlinelibrary.wiley.com/doi/10.1002/app.13689/full.

[18] Qian, X.D., et al., (2011) Combustion and Thermal Degradation Mechanism of a Novel Intumescent Flame Retardant for Epoxy Acrylate Containing Phosphorus and Nitrogen, Industrial \& Engineering Chemistry Research, 50:1881-1892, http://pubs.acs.org/doi/abs/10.1021/ie102196k.

[19] Jimenez, M., Duquesne S. and Bourbigot S., (2006) Intumescent fire protective coating: Toward a better understanding of their mechanism of action, Thermochimica Acta, 449:16-26, http://www.sciencedirect.com/science/article/pii/S0040603106003972.

[20] Price, D., et al.,(2002) Flame retardance of poly(methyl methacrylate) modified with phosphoruscontaining compounds, Polymer Degradation and Stability,77: 227-233, http://www.sciencedirect.com/science/article/pii/S0141391002000381.

[21] Chougrani, K., et al.,(2008) New N,N-amino-diphosphonate-containing methacrylic derivatives, their syntheses and radical copolymerizations with MMA, European Polymer Journal,44:1771-1781, http://cat.inist.fr/?aModele=afficheN\&cpsidt=20444011.

[22] Hayashida, K., et al.,(2002) Flame retarding mechanism of polycarbonate containing trifunctional phenylsilicone additive studied by analytical pyrolysis techniques, Polymer Bulletin, 48:483-490, http://link.springer.com/article/10.1007/s00289-002-0063-6\#.

[23] Canadell, J., Mantechn A., and Cadiz V., (2007) Microwave-accelerated polymerization of 2phenoxymethyl-1,4,6-trioxaspiro[4,4]nonane with diglycidyl ether of bisphenol A, Macromolecular Chemistry and Physics, 208:2018-2025, http://onlinelibrary.wiley.com/doi/10.1002/macp.200700157/full.

[24] Braun, U. and Schartel B., (2004) Flame retardant mechanisms of red phosphorus and magnesium hydroxide in high impact polystyrene, Macromolecular Chemistry and Physics, 205:2185-2196, http://onlinelibrary.wiley.com/doi/10.1002/macp.200400255/full.

[25] Kong, Q.H., Lv R.B. and Zhang S.J.,(2008) Flame retardant and the degradation mechanism of high impact polystyrene/Fe-montmorillonite nanocomposites, Journal of Polymer Research, 15:453-458, http://link.springer.com/article/10.1007/s10965-008-9191-5\#.

[26] Wu, K., et al., (2009) Synthesis and characterization of a functional polyhedral oligomeric silsesquioxane and its flame retardancy in epoxy resin, Progress in Organic Coatings, 65:490-497, http://www.sciencedirect.com/science/article/pii/S0300944009000848.

[27] Wu, K., et al., (2009) Synthesis and characterization of a functional polyhedral oligomeric silsesquioxane and its flame retardancy in epoxy resin, Progress in Organic Coatings, 65:490-497. 
[28] Hsiue, G.H., et al., (2001) Novel phosphorus-containing dicyclopentadiene-modified phenolic resins for flame-retardancy applications, Journal of Applied Polymer Science, 79:342-349,

http://onlinelibrary.wiley.com/doi/10.1002/1097-4628(20010110)79:2\%3C342::AID-

APP180\%3E3.0.CO;2-8/full

[29] Bugajny, M., et al., (1999) The origin and nature of flame retardance in ethylene-vinyl acetate copolymers containing hostaflam AP 750, Polymer International, 48(4): p. 264-270,

http://onlinelibrary.wiley.com/doi/10.1002/(SICI)1097-0126(199904)48:4\%3C264::AID-

PI118\%3E3.0.CO;2-M/abstract. 